\title{
1,3,5-Tris(hydrogensulfato) Benzene: A New and Efficient Catalyst for Synthesis of 4,4'-(arylmethylene)bis(1H-pyrazol-5-ol) Derivatives
}

\author{
Zahed KARIMI-JABERI*, Baharak POOLADIAN, Masoud MORADI, Ehsan GHASEMI \\ Department of Chemistry, Firoozabad Branch, Islamic Azad University, P.O. Box 74715-117 Firoozabad, Fars, Iran
}

\begin{abstract}
Tris(hydrogensulfato) benzene (THSB) was easily prepared by the reaction between phloroglucinol and chlorosulfonic acid in dichloromethane at room temperature. This compound was then used as an efficient catalyst for the synthesis of 4,4'-(arylmethylene)bis( $1 \mathrm{H}$-pyrazol-5-ols) through the condensation reactions of 1-phenyl-3-methylpyrazol-5-one with several different aromatic aldehydes in ethanol at $75^{\circ} \mathrm{C}$. The present methodology offers several advantages over existing methodologies, such as excellent yields, simple procedure, easy work-up and ecofriendly reaction conditions.
\end{abstract}

Key words: 1,3,5-tris(hydrogensulfato) benzene; aromatic aldehydes; 1-phenyl-3-methylpyrazol-5-one; 4,4'-(arylmethylene)bis(1H-pyrazol-5-ols); ethanol; multicomponent reaction

CLC number: $\mathrm{O643} \quad$ Document code: A

Received 30 July 2012. Accepted 9 October 2012.

*Corresponding author. Tel: +98-917-107-6935; Fax: +98-712-6224402; E-mail: zahed.karimi@yahoo.com

English edition available online at Elsevier ScienceDirect (http://www.sciencedirect.com/science/journal/18722067).

Heterocycles represent the largest of the classical divisions in organic chemistry by far and are of immense importance both biologically and industrially. Pyrazoles are an important class of heterocyclic compound. Examination of the chemical literature reveals that a great many synthetic pyrazole derivatives have been reported, with applications across a wide range of fields, where they have been used as pharmaceuticals, agrochemicals, and photographic agents. 2,4-Dihydro-3H-pyrazol-3-one derivatives, including the 4,4'-(arylmethylene)bis( $1 H$-pyrazol-5-ols) have a broad spectrum of approved biological activity, and have been used as anti-inflammatory [1], antipyretic [2], gastric secretion stimulatory [3], antidepressant [4], antibacterial [5], antiviral [6], and antifilarial agents [7]. They have also used as fungicides [8], insecticides [9], and dyestuffs [10-13].

Over the years, multicomponent reactions [14-16] (MCRs) have become increasingly popular as tools for enabling the introduction of sufficient molecular diversity and complexity. These reactions have gained significant popularity in recent years because of their atom-economy and straightforward reaction design, which also allows for substantial minimization in the levels of waste generated from the process with considerable saving in labor, time, and costs [17-19]. MCRs leading to the generation of interesting heterocyclic scaffolds are particularly useful for the construction of diverse chemical libraries of 'drug like' molecules.

Recently, several different three component one-pot condensation reactions have been reported between 1-phenyl-3- methylpyrazol-5-one and a variety of different aldehydes for the construction of 4,4'-(arylmethylene)bis(1H-pyrazol-5-ol) derivatives [6, 20-32]. Several different catalysts have been reported to promote this reaction, including ceric ammonium nitrate (CAN) [6], sodium dodecyl sulfate (SDS) as a surfactant catalyst [20], ETBA [21], $\mathrm{NaBr}$ [22], [Cu(3,4-tmtppa)]( $\left.\mathrm{MeSO}_{4}\right)_{4}$ [23], silica-bonded S-sulfonic acid (SBSSA) [24], silica sulfuric acid (SSA) [25], $\mathrm{H}_{2} \mathrm{O}$ [26], sulfuric acid ([3-(3-silicapropyl)sulfanyl] propyl)ester (SASPSPE) [27], xanthan sulfuric acid [28], $\mathrm{PEG-SO} \mathrm{H}_{3}$ [29], ionic liquid [HMIM]HSO 4 [30], 3-minopropylated silica gel (AP-SiO2) [31], and phosphomolybdic acid [32].

Although some of these methods afford moderate to high yields of the corresponding products, the majority suffer from one or more of the following disadvantages, including (1) the use of a costly catalyst; (2) the requirement for a tedious work-up procedure; (3) the need for high temperatures; and (4) long reaction times. Herein, we report the development of a mild, efficient, and environmentally benign procedure for the synthesis of 4,4'-(arylmethylene)bis (1H-pyrazol-5-ol) derivates from the condensation reaction of aldehydes and 1-phenyl-3-methylpyrazol-5-one in the presence of 1,3,5-tris(hydrogensulfato) benzene (THSB) as an efficient and new catalyst.

\section{Experimental}

\subsection{General}


All of the chemicals were purchased from Merck and Aldrich. Melting points were determined in open capillary tubes and are uncorrected. IR measurements were carried out using $\mathrm{KBr}$ pellets on a Fourier transform infrared (FT-IR) spectrometer (Manufacturer, City, State/Country). ${ }^{1} \mathrm{H}(250 \mathrm{MHz})$ and ${ }^{13} \mathrm{C}(62.5 \mathrm{MHz})$ NMR spectra were recorded on a Bruker Avance 250 spectrometer (Bruker, City, State/Country) in DMSO- $\mathrm{d}_{6}$ using tetramethylsilane (TMS) as an internal reference. All of the products have been reported previously in the literature and were characterized according to their spectral and physical data. Reaction monitoring for the progress of all of the reactions was carried out by thin-layer chromatography (TLC) using silica gel $60 \mathrm{GF}_{245}$ precoated sheets and were visualized using a UV-lamp at a wave length of $254 \mathrm{~nm}$. All chemicals and solvents were of reagent grade and the latter were distilled and dried before use. The elemental analyses were performed with an Elementar Analysensysteme GmbH VarioEL in CHNS mode.

\subsection{Preparation of THSB}

A solution of chlorosulfonic acid (8.74 g, ca. $5 \mathrm{ml}, 75$ $\mathrm{mmol}$ ) in $\mathrm{CH}_{2} \mathrm{Cl}_{2}(20 \mathrm{ml})$ was added to phloroglucinol (3.15 g, $25 \mathrm{mmol}$ ) in a drop-wise manner over a period of $1 \mathrm{~h}$ at room temperature (Scheme 1). $\mathrm{HCl}$ evolved immediately. Upon completion of the addition, the mixture was shaken for $3 \mathrm{~h}$, and the residual $\mathrm{HCl}$ was removed by suction. The solid residue was washed with $n$-hexane $(10 \mathrm{ml})$ and filtered to give the desired product as a yellow solid material in $95 \%$ yield.

\subsection{General procedure for the one-pot synthesis of 4,4'-(arylmethylene)bis(1H-pyrazol-5-ol) derivatives}

THSB (0.04 mmol, $0.014 \mathrm{~g})$ and silica gel (0.006 g) were added to a solution of aromatic aldehyde 1 (1 mmol, Scheme 2) and 1-phenyl-3-methylpyrazol-5-one 2 (2 mmol, scheme 2 ) in ethanol (2 $\mathrm{ml})$, and the resulting mixture was stirred at $75^{\circ} \mathrm{C}$ for the specified period of time, as indicated in Table 1. Upon completion of the reaction, as confirmed by TLC, the reaction mixture was cooled to room temperature. The resulting precipitated product was then filtered and washed with $n$-hexane $(10 \mathrm{ml})$ to afford the pure product 3 (3a-3u) as a white powder.

\subsection{Characterization of some representative compounds}

THSB. Pale yellow solid. IR $\left(\mathrm{KBr}, \mathrm{cm}^{-1}\right)$ : 3403, 1284, 1174, 578. ${ }^{1} \mathrm{H}$ NMR (250 MHz, DMSO-d $\mathrm{d}_{6}$ ): 5.82 (s, 3H, ArH). Anal. Calcd For $\mathrm{C}_{6} \mathrm{H}_{6} \mathrm{O}_{12} \mathrm{~S}_{3}$ : C, 19.67; H, 1.65; S, 26.26; Found: C, 19.57; H, 1.59; S, 26.19.

4,4'-[(4-Chloro-3-nitrophenyl)methylene]bis(3-methyl-1phenyl-1H-pyrazol-5-ol) (Table 1, Entry 10, 3j). Pale yellow solid. IR $\left(\mathrm{KBr}, \mathrm{cm}^{-1}\right)$ : 3425, 3054, 2923, 1598, 1570, 1530, 1501, 1368, 750. ${ }^{1} \mathrm{H}$ NMR (250 MHz, DMSO-d $_{6}$ ): $2.32\left(\mathrm{~s}, 6 \mathrm{H}, 2 \mathrm{CH}_{3}\right), 5.80(\mathrm{~s}, 1 \mathrm{H}, \mathrm{CH}), 7.23$ (d, $2 \mathrm{H}, J=2.5 \mathrm{~Hz}, \mathrm{ArH}), 7.25$ (d, $4 \mathrm{H}, J=2.5 \mathrm{~Hz}, \mathrm{ArH})$, 7.54-7.57 (m, 1H, ArH), 7.65-7.66 (m, 5H, ArH), 7.84 (s, $1 \mathrm{H}, \mathrm{ArH}) ;{ }^{13} \mathrm{C}$ NMR (62.5 MHz, DMSO- $\mathrm{d}_{6}$ ): 11.9, 104.1, 121.1, 122.9, 124.6, 126.2, 129.1, 129.4, 131.7, 133.3, 137.4, 144.0, 146.7, 147.8. Anal. Calcd For $\mathrm{C}_{27} \mathrm{H}_{22} \mathrm{C}_{1} \mathrm{~N}_{5} \mathrm{O}_{4}$ : C, 62.85; H, 4.30; N, 13.57; Found: C, 62.74; H, 4.25; N, 13.50 .

4,4'-[(2-Methoxyphenyl)methylene]bis(3-methyl-1-pheny l-1H-pyrazol-5-ol) (Table 1, Entry 14, 3n). Yellow solid. IR $\left(\mathrm{KBr}, \mathrm{cm}^{-1}\right)$ : 3427, 3062, 2922, 1598, 1575, 1497, 1241, 756. ${ }^{1} \mathrm{H}$ NMR (250 MHz, DMSO-d $\mathrm{d}_{6}$ ): 2.26 (s, 6H, 2CH ), 3.79 (s, 3H, $\mathrm{OCH}_{3}$ ), 5.18 (s, $\left.1 \mathrm{H}, \mathrm{CH}\right), 6.82-6.93$ (m, 2H, ArH), 7.11-7.24 (m, 3H, ArH), 7.41 (t, 4H, $J=7$ Hz, ArH), 7.60 (d, $1 \mathrm{H}, J=7.5 \mathrm{~Hz}, \mathrm{ArH}), 7.67-7.70$ (m, 4H, ArH); ${ }^{13} \mathrm{C}$ NMR (62.5 MHz, DMSO-d $\mathrm{d}_{6}$ ): 12.0, 27.8, 55.9, 111.2, 120.4, $121.0,125.9,127.7,128.9,129.3,130.5,130.7,130.9$, 131.1, 146.6, 156.2. Anal. Calcd For $\mathrm{C}_{28} \mathrm{H}_{26} \mathrm{~N}_{4} \mathrm{O}_{3}$ : C, 72.09; H, 5.62; N, 12.01; Found: C, 71.98; H, 5.57; N, 11.93.

1,4-Diphenylene-4,4'-(methylene)bis(3-methyl-1-phenyl1H-pyrazol-5-ol) (Table 2, 3u). White cream solid. IR (KBr, $\left.\mathrm{cm}^{-1}\right)$ : 3415, 3026, 1590, 1495, 1410, 1350, 1290, 1120, 1020, 860, 745, 690. ${ }^{1} \mathrm{H}$ NMR (250 MHz, DMSO-d $\left.\mathrm{d}_{6}\right): 2.28$ (s, 12H, $\mathrm{CH}_{3}$ ), 5.07 (s, 2H, CH), 7.17 (s, 4H, CH), 7.23 (t, $4 \mathrm{H}, J=7.1 \mathrm{~Hz}, \mathrm{Ar}), 7.41$ (t, 8H, $J=7.8 \mathrm{~Hz}, \mathrm{Ar}), 7.69$ (d, $8 \mathrm{H}, J=7.9 \mathrm{~Hz}, \mathrm{Ar}), 12.43$ (br, 2H, OH) 14.10 (2H, s, OH); ${ }^{13} \mathrm{C}$ NMR (62.5MHz, DMSO- $\mathrm{d}_{6}$ ): 12.6, 33.6, 121.5, 128.0, 129.7, 140.9, 147.0, 155.0. Anal. Calcd for $\mathrm{C}_{48} \mathrm{H}_{42} \mathrm{~N}_{8} \mathrm{O}_{4}$ : C, 72.52; H, 5.32; N, 14.09; Found: C, 72.35; H, 5.29; N, 13.85 .

\section{Results and discussion}

1,3,5-Tris(hydrogensulfato) benzene (THSB) was easily<smiles>Oc1cc(O)cc(O)c1</smiles>

Scheme 1. Preparation of THSB. 


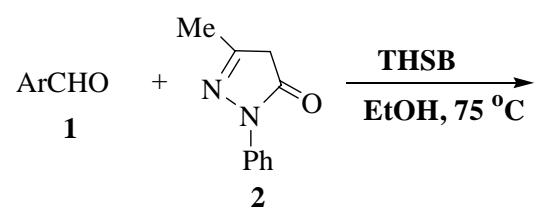

2<smiles>Cc1nn(-c2ccccc2)c(O)c1C([Al])c1n[nH]c(O)c1C</smiles>

$85 \%-98 \%$

21 examples

Scheme 2. Synthesis of the 4,4'-(arylmethylene)bis(1H-pyrazol-5-ol) derivatives catalyzed by THSB.

prepared by the addition of chlorosulfonic acid to phloroglucinol (1,3,5-benzenetriol) at room temperature. This reaction proceeded smoothly and cleanly, with $\mathrm{HCl}$ gas being immediately evolved from the reaction mixture. Furthermore, the catalyst itself was safe and easy to handle (Scheme 1).

In connection with our ongoing work towards the development of new synthetic routes for the construction of complex heterocyclic compounds, such as the newly discovered 2-amino-4H-pyran-3-carbonitriles [33], 2,3-dihydro quinazolin-4(1H)-ones [34], tetrahydrobenzo[a]xanthen-11-ones [35], and dihydropyrano[2,3-c]pyrazoles [36], herein we report the three-component condensation reaction of aromatic aldehydes 1 with 1-phenyl-3-methylpyrazol-5-one 2 in ethanol in the presence of THSB as a novel catalyst with a reaction time of 2-5 min, allowing for the one-pot formation of 4,4'-(arylmethylene)bis( $1 H$-pyrazol-5-ols) 3 in ex- cellent yields (Scheme 2).

For the initial optimization of the reaction conditions, the condensation reaction of 4-chlorobenzaldehyde with 1-phenyl-3-methylpyrazol-5-one was investigated in ethanol as a model reaction. The best result was achieved when 4-chlorobenzaldehyde was reacted with 1-phenyl-3methylpyrazol-5-one (in a 1:2 molar ratio) in the presence of THSB (X wt\%) at $75{ }^{\circ} \mathrm{C}$ for $2 \mathrm{~min}$ (Table 1, entry 2).

These conditions were therefore selected as the optimized conditions and employed for the condensation reaction of a variety of different aryl aldehydes with 3-methyl-l-phenyl5-pyrazolone to give the corresponding 4,4'-(arylmethylene) bis(3-methyl-1-phenyl-1H-pyrazol-5-ol) derivatives. The results are summarized in Table 1.

As shown in Table 1, all of the aromatic aldehydes 1 reacted successfully with 1-phenyl-3-methylpyrazol-5-one $\mathbf{2}$ in the presence of THSB in ethanol at $75{ }^{\circ} \mathrm{C}$, to afford the

Table 1 Synthesis of 4,4'-(arylmethylene)bis(1H-pyrazol-5-ols)

\begin{tabular}{|c|c|c|c|c|c|c|}
\hline \multirow{2}{*}{ Entry } & \multirow{2}{*}{$\mathrm{Ar}$} & \multirow{2}{*}{ Product } & \multirow{2}{*}{ Time (min) } & \multirow{2}{*}{ Isolated yield (\%) } & \multicolumn{2}{|c|}{ Melting point $\left({ }^{\circ} \mathrm{C}\right)$} \\
\hline & & & & & This work & Reported \\
\hline 1 & $\mathrm{C}_{6} \mathrm{H}_{5}$ & $3 a$ & 5 & 93 & $169-171$ & $170-172$ [25] \\
\hline 2 & $4-\mathrm{ClC}_{6} \mathrm{H}_{4}$ & $3 \mathbf{b}$ & 2 & 95 & $215-216$ & $215-217$ [25] \\
\hline 3 & $2-\mathrm{ClC}_{6} \mathrm{H}_{4}$ & $3 c$ & 2 & 95 & $235-237$ & $235-237$ [25] \\
\hline 4 & $4-\mathrm{BrC}_{6} \mathrm{H}_{4}$ & 3d & 3 & 98 & $183-185$ & $183-185$ [26] \\
\hline 5 & $4-\mathrm{FC}_{6} \mathrm{H}_{4}$ & $3 \mathbf{e}$ & 3 & 90 & $182-184$ & $182-184$ [32] \\
\hline 6 & $4-\mathrm{CNC}_{6} \mathrm{H}_{4}$ & $3 f$ & 3 & 98 & $212-214$ & $210-212$ [25] \\
\hline 7 & $4-\mathrm{NO}_{2} \mathrm{C}_{6} \mathrm{H}_{4}$ & $3 g$ & 3 & 96 & 225 & $224-226$ [32] \\
\hline 8 & $3-\mathrm{NO}_{2} \mathrm{C}_{6} \mathrm{H}_{4}$ & $3 \mathbf{h}$ & 4 & 95 & $151-154$ & $152-154$ [32] \\
\hline 9 & $2,4-\mathrm{Cl}_{2} \mathrm{C}_{6} \mathrm{H}_{3}$ & $3 \mathbf{i}$ & 3 & 98 & $227-229$ & $227-229$ [24] \\
\hline 10 & 4-Cl-3- $\mathrm{NO}_{2} \mathrm{C}_{6} \mathrm{H}_{3}$ & $3 \mathbf{j}$ & 2 & 95 & $237-238$ & - \\
\hline 11 & $4-\mathrm{CH}_{3} \mathrm{C}_{6} \mathrm{H}_{4}$ & $3 \mathbf{k}$ & 3 & 92 & $201-203$ & $202-204$ [25] \\
\hline 12 & $3-\mathrm{CH}_{3} \mathrm{C}_{6} \mathrm{H}_{4}$ & 31 & 4 & 90 & $238-241$ & $242-243[28]$ \\
\hline 13 & $4-\mathrm{OCH}_{3} \mathrm{C}_{6} \mathrm{H}_{4}$ & $3 m$ & 3 & 90 & $176-179$ & $176-178$ [32] \\
\hline 14 & $2-\mathrm{OCH}_{3} \mathrm{C}_{6} \mathrm{H}_{4}$ & $3 n$ & 5 & 90 & $211-214$ & $210-213$ [30] \\
\hline 15 & $4-\mathrm{OHC}_{6} \mathrm{H}_{4}$ & 30 & 5 & 90 & $154-157$ & $155-157$ [24] \\
\hline 16 & 2-pyridyl- & $3 p$ & 3 & 98 & 229-231 & $232-233[6]$ \\
\hline 17 & 3-pyridyl- & $3 q$ & 3 & 95 & $239-240$ & $238-240$ [25] \\
\hline 18 & 2-naphthyl- & $3 r$ & 3 & 95 & 204-206 & $206-208$ [25] \\
\hline 19 & 2-furyl- & $3 s$ & 3 & 95 & 188-191 & $188-190$ [32] \\
\hline 20 & $\left(\mathrm{CH}_{3}\right)_{2} \mathrm{CH}$ & $3 t$ & 3 & 90 & $211-212$ & $213-214$ [32] \\
\hline $21^{\mathrm{a}}$ & $\mathrm{CHOC}_{6} \mathrm{H}_{4}$ & $3 \mathbf{u}$ & 5 & 85 & $209-212$ & $214-216$ [27] \\
\hline
\end{tabular}

Reaction conditions: Aromatic aldehyde (1 mmol), 1-phenyl-3-methylpyrazol-5-one (2 mmol), THSB (0.014 g), $75^{\circ} \mathrm{C}, \mathrm{EtOH}(2 \mathrm{ml})$.

${ }^{a}$ Reaction conditions: terephthaldehyde (1 mmol), 1-phenyl-3-methylpyrazol-5-one (4 mmol), THSB (0.014 g), 75 $\mathrm{C}, \mathrm{EtOH}(2 \mathrm{ml})$. 
Table 2 Comparison of the results obtained using THSB with other catalyst for the synthesis of the 4,4'-(arylmethylene)bis(1H-pyrazol-5-ols)

\begin{tabular}{|c|c|c|c|c|}
\hline Entry & Reagent and conditions & Time (min) & Yield (\%) & Ref \\
\hline 1 & CAN (5 mol\%), $\mathrm{H}_{2} \mathrm{O}, \mathrm{RT}$ & $10-25$ & $88-94$ & {$[6]$} \\
\hline 2 & SBSSA (0.1 g), EtOH (10 ml), reflux & $40-240$ & $80-90$ & {$[24]$} \\
\hline 3 & SSA (0.08 g), EtOH: $\mathrm{H}_{2} \mathrm{O}(10 \mathrm{ml}), 70^{\circ} \mathrm{C}$ & 20-150 & $78-93$ & {$[25]$} \\
\hline 4 &,$- \mathrm{H}_{2} \mathrm{O}(20 \mathrm{ml})$, Reflux & $360-480$ & $72-84$ & {$[26]$} \\
\hline 5 & SASPSPE (0.1 g), EtOH (10 ml), reflux & $120-240$ & $75-90$ & {$[27]$} \\
\hline 6 & xanthan sulfuric acid (0.08 g), EtOH (5 ml), reflux & $15-30$ & $76-95$ & [28] \\
\hline 7 & PEG-SO ${ }_{3} \mathrm{H}$ (1.5 mol\%), $\mathrm{H}_{2} \mathrm{O}$, Reflux & $15-120$ & $76-94$ & {$[29]$} \\
\hline 8 & {$\left[\mathrm{HMIM} \mathrm{HSO}_{4}\right.$ (10 mol\%), EtOH, RT } & $20-75$ & $40-92$ & {$[30]$} \\
\hline 9 & $\mathrm{AP}-\mathrm{SiO}_{2}(3.22 \mathrm{~g}), \mathrm{CH}_{3} \mathrm{CN}$ (10 ml), RT & $5-45$ & $90-98$ & {$[31]$} \\
\hline 10 & phosphomolybdic acid (10 mol\%), EtOH (5 ml), RT & $210-330$ & $91-96$ & [32] \\
\hline 11 & THSB (0.014 g), EtOH $(2 \mathrm{ml}), 75^{\circ} \mathrm{C}$ & $2-5$ & $90-98$ & present method \\
\hline
\end{tabular}

corresponding products 3 in excellent yields. Aromatic aldehydes containing electron-withdrawing (e.g., nitro and halide groups) and electron-donating groups (e.g., hydroxyl and alkoxy groups) were employed and reacted well to give the corresponding products $\mathbf{3}$ in excellent yields under these reaction conditions, leading to the conclusion that the electronic nature of the substituents on the aromatic ring had no discernible impact on the course of the reaction.

The practicality and synthetic efficiency of this reaction was highlighted by the reaction of terephthaldehyde with 1-phenyl-3-methylpyrazol-5-one to give structurally complex di(bis-pyrazol-5-ol) Table 1 [25,27].

To highlight the advantages of the THSB catalyst over the other catalysts reported in the literature, the results obtained using this catalyst were compared with those obtained from other catalysts for the synthesis of 4,4'-(arylmethylene) bis(1H-pyrazol-5-ols). From Table 2, it is clear that THSB appeared to promote the reaction more effectively than a number of other catalysts, particularly in terms of the time required to complete the reaction and the reaction yield. This method offers some advantages in terms of very fast reaction times, simplicity of performance, low cost, and it follows along the line of green chemistry.

\section{Conclusions}

In conclusion, we have described the development of an efficient one-pot three-component condensation reaction of aromatic aldehydes with 1-phenyl-3-methylpyrazol-5-one in ethanol for the synthesis of 4,4'-(arylmethylene)bis( $1 H$ pyrazol-5-ol) derivatives, with the process being catalyzed by 1,3,5-tris(hydrogensulfato) benzene (THSB) as a novel catalyst. This new method has the advantages of higher yields, mild reaction conditions, shorter reaction times, and is a convenient and environmental friendly procedure. We are currently exploring further applications of the THSB catalyst to other organic reactions in our laboratory.

\section{References}

1 Sugiura S, Ohno S, Ohtani O, Izumi K, Kitamikado T, Asai H, Kato K, Hori M, Fujimura H. J Med Chem, 1977, 20: 80

2 Behr L C, Fusco R, Jarboe C H. In: Weissberger A ed. The Chemistry of Heterocyclic Compounds, Pyrazoles, Pyrazolines, Pyrazolidines, Indazoles, and Condensed Rings. New York: Interscience, 1967. 22

3 Rosiere C E, Grossman M I. Science, 1951, 113: 651

4 Bailey D M, Hansen P E, Hlavac A G, Baizman E R, Pearl J, Defelice A F, Feigenson M E. J Med Chem, 1985, 28: 256

5 Mahajan R N, Havaldar F H, Fernandes P S. J Indian Chem Soc, 1991, 68: 245

6 Sujatha K, Shanthi G, Selvam N P, Manoharan S, Perumal P T, Rajendran M. Bioorg Med Chem Lett, 2009, 19: 4501

7 Chauhan P M S, Singh S, Chatterjee R K. Indian J Chem Sect B, 1993, 32: 858

8 Singh D, Singh D. J Indian Chem Soc, 1991, 68: 165

9 Lubs H A. The Chemistry of Synthetic Dyes and Pigments. Washington DC: American Chemical Society, 1970.

10 Uzoukwu A B, Al-Juaid S S, Hitchcock P B, Smith J D. Polyhedron, 1993, 12: 2719

11 Maurya R C, Verma R. Indian J Chem Sect A, 1997, 36: 596

12 Garnovskii A D, Uraev A I, Minkin V I. Arkivoc, 2004, (3): 29

13 Pettinari C, Marchetti F, Pettinari R, Drozdov A, Troyanov S, Voloshin A I, Shavaleen N M. J Chem Soc Dalton Trans, 2002, 1409

14 Cariou C C A, Clarkson G J, Shipman M. J Org Chem, 2008, 73: 9762

15 Candeias N R, Montalbano F, Cal P M S D, Gois P M P. Chem Rev, 2010, 110: 6169

16 Banfi L, Basso A, Giardini L, Riva R, Rocca V, Guanti G. Eur J Org Chem, 2011: 100

17 Basso A, Banfi L, Riva R, Guanti G. J Org Chem, 2005, 70: 575

18 Yue T, Wang M X, Wang D X, Masson G, Zhu J P. J Org Chem, 2009, 74: 8396

19 Trofimov B A, Andriyankova L V, Belyaeva K V, Malkina A G, Nikitina L P, Afonin A V, Ushakov I A. Eur J Org Chem, 2010: 
1772

20 Wang W, Wang S X, Qin X Y, Li J T. Synth Commun, 2005, 35: 1263

21 Shi D Q, Chen J, Wu N, Zhuang Q Y, Wang X S. Chin J Org Chem, 2005, 25: 405

22 Elinson M N, Dorofeev A S, Nasybullin R F, Nikishin G I. Synthesis, 2008: 1933

23 Sobhani S, Safaei E, Hasaninejad A R, Rezazadeh S. J Organomet Chem, 2009: 694: 3027

24 Niknam K, Saberi D, Sadegheyan M, Deris A. Tetrahedron Lett, 2010, 51: 692

25 Niknam K, Mirzaee S. Synth Commun, 2011, 41: 2403

26 Tale N P, Tiwari G B, Karade N N. Chin Chem Lett, 2011, 22: 1415

27 Tayebi S, Baghernejad M, Saberi D, Niknam K. Chin J Catal (催化学报), 2011, 32: 1477
28 Suresh Kuarm B, Rajitha B. Synth Commun, 2012, 42: 2382

29 Hasaninejad A, Shekouhy M, Zare A, Ghattali S M S H, Golzara N. J Iran Chem Soc, 2011, 8: 411

30 Zang H J, Su Q H, Mo Y M, Cheng B. Ultrason Sonochem, 2011, 18: 68

31 Sobhani S, Hasaninejad A R, Faal Maleki M, Pakdin Parizi Z. Synth Commun, 2012, 42: 2245

32 Phatangare K R, Padalkar V S, Gupta V D, Patil V S, Umape P G, Sekar N. Synth Commun, 2012, 42: 1349

33 Karimi-Jaberi Z, Pooladian B. Sci World J, 2012: 208796

34 Karimi-Jaberi Z, Arjmandi R. Monatsh Chem, 2011, 142: 631

35 Karimi-Jaberi Z, Abbasi S Z, Pooladian B, Jokar M. E-J Chem, 2011, 8: 1895

36 Karimi-Jaberi Z, ReyazoShams M M. Heterocycl Commun, 2011, 17: 177 